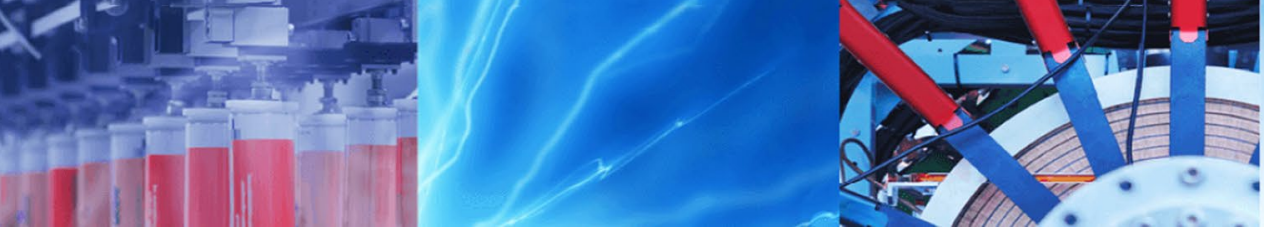

Research Article

\title{
The dynamic performance of novel multilayered hybrid composite laminate
}

\author{
Sai Krishna Chitturi ${ }^{1}$ (D) A. A. Shaikh ${ }^{1}$
}

Received: 14 November 2019 / Accepted: 25 April 2020 / Published online: 2 May 2020

(c) Springer Nature Switzerland AG 2020

\begin{abstract}
Due to an increase in the need for improvement of impact resistance of conventional composites, hybrid composites are evolved. This research article presents the dynamic characteristics of a novel two-component hybrid composite plate under transverse impact loading. The multilayered hybrid composite laminate is fabricated using woven fibreglass fabric as skin material and thermoplastic polycarbonate sheet as the core. High strength, medium viscous epoxy matrix is used for bonding the skin and core materials. The hand layup followed by a compression molding technique is used for producing the laminate. The test samples are impacted with a minimum energy of $45 \mathrm{~J}$ to a maximum energy of $60 \mathrm{~J}$ to obtain rebound, penetration and perforation phenomenon at room temperature. Load-energy-displacement-time curves are plotted to understand the transient behaviour of the composite plates. Results are compared with the pure counterparts available in the literature in terms of impact resistance. It is inferred that the novel multilayered laminate being in lightweight about $19.17 \%$ as compared to conventional laminate presented by Evci and Gülgeç ( $\mathrm{J}$ Compos Mater 48:3215-3236). Further, the novel composite has provided less damage area with $16.66 \%$ of enhanced impact resistance in terms of energy required for complete perforation. The investigation revealed the possibility of replacing conventional materials with hybrid laminates in structural, defense and automotive applications, where impact resistance and light weight has much importance.
\end{abstract}

Keywords Multilayered hybrid composite · Thermoplastic sheet $\cdot$ Hand layup · Dynamic performance

\section{Introduction}

The composites are exploited as elements of multidisciplinary systems. In addition to this, there is a huge demand for these composite in the defense sector as an armour solution [1]. The ease of manufacturing, improved performance in terms of strength and flexible yet lightweight are the considerations for having a wide spectrum of their applications [2]. Understanding the performance of composites under impact loads is always a challenging task for the researcher as it involves various parameters. Unlike medium and high-velocity impact scenarios, transverse impact under low velocity leaves an unavoidable and notable loss of strength with barely visible damage, which in turn taken the attention of researchers to develop newer materials with hybridization technique. According to Kretsis et al. [3] types of hybrid composites include: (1) interply/multi-layer (layer-by-layer) hybrids, (2) intraply/ commingled (yarn-by-yarn) hybrids, (3) intimately/randomly (fiber-by-fiber) mixed hybrids, (4) sandwich like hybrid composite structures. The employment of composites exposes to transverse dynamic impact loads are taken cautiously as impacts may occur during manufacture, normal operations, maintenance and so on [4]. Fullcomposite body structures, especially in automotive and aviation applications, are becoming a proper replacement

Sai Krishna Chitturi, saikrishna.mech@gmail.com | ${ }^{1}$ Department of Mechanical Engineering, Sardar Vallabhbhai National Institute of Technology, Surat, India. 
for current metal ones. For this reason, damage to such structures subjected to impact is a crucial case study in current research [5].

Apart from conventionally used kevlar material, lowcost glass-reinforced polymer composites are also in use. But due to the dearth of plastic deformation mode, they exhibit poor resistance to take in the impact energy. The brittle nature of glass-reinforced polymers makes them very susceptible even for low-velocity impact loads. To surpass the energy absorption potential of conventional composites, materials with high strain to failure and toughness are used in conjunction with base composites. This approach leads to the development of hybrid composites. For instigating hybrid composites, the research community took a step in combining materials having high stiffness with materials possessing high toughness. A trade-off between structural accomplishment and toughness could be achieved in hybrid composites with acceptable loadbearing capacity and enhanced energy absorption [6].

Numerous works have been reported over the investigation of the dynamic response of composites with different effecting parameters such as materials, laminate processing and test conditions over a wide variety of material combinations. Which includes Fiber type [7-9], total fiber content or fiber volume fraction [10], resin type [11],stacking arrangement [12-16], reinforcement geometry [17], weaving density and curing pressure [18], sandwich construction [19], ambient temperature [20], laminate thickness [21,22], impactor nose diameters and nose shapes [4, 23], Hybridization [24-30].

Thanomsilp et al. [8] conducted experimental analysis to find the impact resistance of commingled yarn fabrics based hybrid composites. The plastic deformation is the significant element behind the enhancement of energy absorbed by the hybrid laminates. The differences are thought to be related to the differences in the bonding between the thermoplastic fibers and the thermosetting matrix. Park et al. [13, 14] carried experimental investigation on glass, aramid fabric for transverse impact loading with different stacking sequences. The authors inferred that, the damage occurred as huge local stress produced near to the point of impact over the impacted side of the sample. The rear side positioning of aramid layer result in higher layer separation area and higher impact energy. The energy dissipation begins in the aramid layers via plastic deformation located at rear side, whilst by placing the aramid layers at the front end experience partial deformation due to restriction towards deformation from subsequent layers. It signifies that the absorption phenomenon governed by extent of deformation at rear end. Hosur et al. [15] employed plain weave glass and twill weave carbon fabric for hybridization. It was concluded that, by aligning high strain to failure material like glass at the bottom in the layup sequence could produce better impact resistance. Zulkafli et al. [16] studied the dynamic performance of banana/glass reinforced polypropylene composite. The study pointed that, incorporation of glass fibers in natural fiber system results in higher absorption rate of energy with enhanced impact resistance. Salehi-Khojin et al. [20] experimentally investigated on effect of temperature on hybridization of kevlar/fiber glass laminate put through transverse impact energy. It was recognized that, the influence of temperature on total incipient energy required for fully perforating the sample will be very little by developing a composite with plain weave fabric architecture, with respect to unidirectional and crossply composites. According to Gustin et al. [24] different modes of failure are the result of variation in peak forces when a kevlar/carbon sandwich composite is subjected to transverse impact loading. This is due to differences in in-plane tensile and interlaminar shear properties for individual sample type. The author pointed that, laminates developed with kevlar exhibit tensile failure modes, implied by bending at the impactor boundary and slitting around the impact center. Sevkat et al. [25-27] examined the effect of hybridization, impactor geometry for low velocity impact tests. From their analysis it was stated that, hybrid composites with glass layers at the outer surface has shown better properties and slowed down the gathering of damage compared to their counterparts. Highest contact force \& maximum deflection for an impact event decreases with an increase in stiffness of the composite by increasing the stiffer fibers. Malingam et al. [28] studied the effect of hybridization on kenaf/glass fiber composite. The author noticed that, aligning glass fibers at the outermost layers leads to impoved specific energy absorption. Kaya [31] bring off the comparison between non-hybrid and intraply hybrid composites made of carbon/E-glass/polypropylene for damage resistance under low velocity impact scenario. There is no positive hybridization was observed in terms of energy absorption whereas the damage area of hybrid composites is smaller correlate with non-hybrid composites. Ying et al. [32] carried out experimental study on interply, intraply and sandwich like interply hybrid composites made of twill weave carbon and aramid fabrics. The samples are tested under same impact energies and concluded that interply hybrid samples having high stiffness carbon fabric at the impact side has highest damage tolerance along with impact resistance as compared with all other set of samples. Isa et al. [33] performed experimental study to perceive the influence of different kinds of fibers and their hybrid combinations. It was observed that positive hybridization effects were observed in terms of density and hybridization improved the tensile and specific in-plane tensile strength enhancement over the pure counter parts. 
From the literature study it is convinced that, the exisiting composites madeup of thermoplastic resin system undergoes specific heat treatment process and hot extraction which in turn affects the properties of developed compoistes. Also, the fabrication of thermoplastic composite becomes costlier due to sophisticated setup. Whereas by adopting thermoset system leaves a brittle kind of composite. To conquer the above challenge and to produce better product with the advantage of both the resin systems, a composite with the combination of multiple class of systems is to be considered.

The present work represents the attempt made in understanding the dynamic performance of multilayered hybrid laminate made with a different class of constituents i.e., woven fibreglass fabric, thermoplastic sheet reinforced with epoxy matrix. Incipient energies are chosen to see the rebound, penetration and perforation phenomenon. The materials and methods with information on dynamic impat test setup is described under the heading of experimental work in Sect. 2. Results and discussion are reported in Sect. 3. Characteristic study of impact resistance and damage phenomenon of novel composition is elucidated on comparison with conventional laminate from literature study. Load versus deflection, load versus time, energy versus time, plots are considered for understanding the laminate behaviour for dynamic loading. Damage mechanism is elucidated with photographic images captured from a rapid-I vision measuring system. The outcomes of the research work are revealed under conclusions in Sect. 4.

\section{Experimental work}

\subsection{Materials and methods}

The multilayered hybrid laminates are prepared from $305 \mathrm{~g} / \mathrm{m}^{2}$ plain weave fibreglass fabric made of glass yarns with 30 yarns/inch in the warp direction and 24 yarns/inch in weft direction were used as a skin and $0.9 \mathrm{~mm}$ thin thermoplastic polycarbonate sheet as core and high strength, medium viscous epoxy resin appropriate for hand layup method. The E-Glass fabric is procured from Om industrial fabrics, Ahmedabad,Gujarat, India. Whereas, general purpose carboron polycarbonate sheets are taken from a local supplier. Lapox ARL-135 epoxy resin with suitable hardner was procured from Atul pvt Itd, Vadodara,Gujarat,India. The closer number of yarns in warp and weft directions assured similar mechanical properties in principal directions. The mechanical characteristics of the constituent materials $[9,34]$ are reported in Table 1 and the basic information regarding novel hybrid composite laminate is documented in Table 2.
Table 1 Mechanical characteristics of constituent materials [9, 34]

\begin{tabular}{llll}
\hline Property/material & Fiberglass & Polycarbonate & Epoxy \\
\hline Density (g/cc) & 2.56 & 1.2 & 1.1 \\
Tensile strength (MPa) & 3500 & 63 & 65 \\
Tensile modulus (GPa) & 72 & 1.5 & 3.1 \\
Elongation (\%) & 2.5 & 60 & 5.5 \\
Poisson's ratio & 0.22 & 0.34 & 0.32 \\
Glass transition Temperature & 210 & 148 & 80 \\
$\left({ }^{\circ} \mathrm{C}\right)$ & & & \\
\hline
\end{tabular}

Table 2 Basic information of composite laminate

\begin{tabular}{llc}
\hline Laminate designation & & $\mathrm{G}_{8} \mathrm{PC}_{1} \mathrm{G}_{8}$ \\
\hline Density (g/cc) & Present work & 1.56 \\
& Evci and Gülgeç [1] & 1.93 \\
Thickness (mm) & $5 \pm 0.1$ & \\
Fiber volume (\%) & Glass & 35.69 \\
& Polycarbonate & 18.90 \\
Total fiber volume (\%) & 54.59 & \\
\hline
\end{tabular}

\subsection{Fabrication of hybrid composite}

A match mold die madeup of M.S.plates are prepared at institute laboratory in different sizes. Additional weights (M.S.plates) of uniform thickness and same size as of mold setup are kept over the match plate to apply a constant pressure of $0.05 \mathrm{~kg} / \mathrm{cm}^{2}$. The wetted constituent layers with resin are arranged symmetrically as presented in Fig. 1. The laminates are allowed to cure at room temperature for $8 \mathrm{~h}$ followed by a temperature of $60^{\circ} \mathrm{C}$ for $4 \mathrm{~h}$ as per the guidelines provided in technical data sheet of epoxy resin. The thickness of the laminate is measured as $5 \mathrm{~mm} \pm 0.1$ with a total constituent volume of $55 \%$. Test samples of size $100 \times 150 \mathrm{~mm}^{2}$ are obtained from cured laminates with the help of in-house abrasive water jet machining.

\subsection{Dynamic impact test setup}

The dynamic impact test was accomplished using Instron drop weight impact test rig, CEAST 9350 equipped with the data recording system. A hemispherical tup having $12.7 \mathrm{~mm}$ nose radius and $5.26 \mathrm{kgs}$ of self-weight was considered for experimentation according to ASTM standard D 7136 [35]. According to the standard implied in the test conditions, the minimum energy required to impact the test sample should be $6.7 \mathrm{~J} / \mathrm{mm}$. Hence central impact test normal to the sample was carried at different incipient energies as per the thickness of the test sample to see the major phenomena of rebound, partial penetration and 
Fig. 1 Schematic representation of multilayered laminate $\left[\mathrm{G}_{8} \mathrm{PC}_{1} \mathrm{G}_{8}\right]$
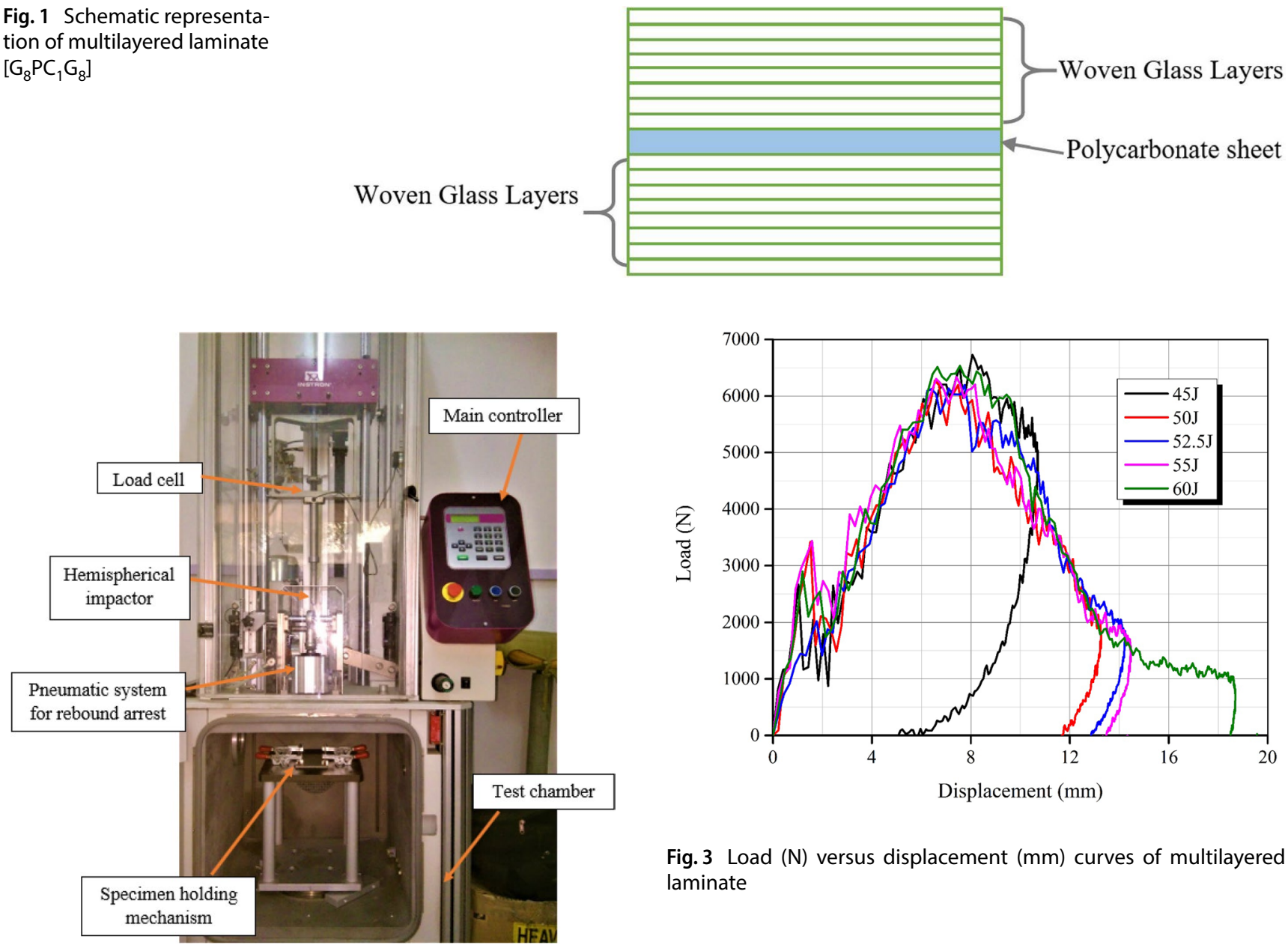

Fig. 2 Instron CEAST 9350 drop weight impact test rig

complete perforation. The test setup is equipped with the pneumatically controlling system for resitriting the impactor from rebounding. At each energy level minimum of 3 samples are tested and their corresponding load, deflection and energy data is collected with respect to time. The impact test rig shown in Fig. 2 is used for conducting all the experiments.

\section{Results and discussion}

Investigation on transverse dynamic impact performance of hybrid composite has been conducted at different incipient energies. The impact damage assessment in different energy zones which are namely rebound, penetration and perforation are interpreted, which are detailed extensively in earlier research works $[4,18,23]$. The recorded data of load, displacement, energy and time from the data acquisition system is

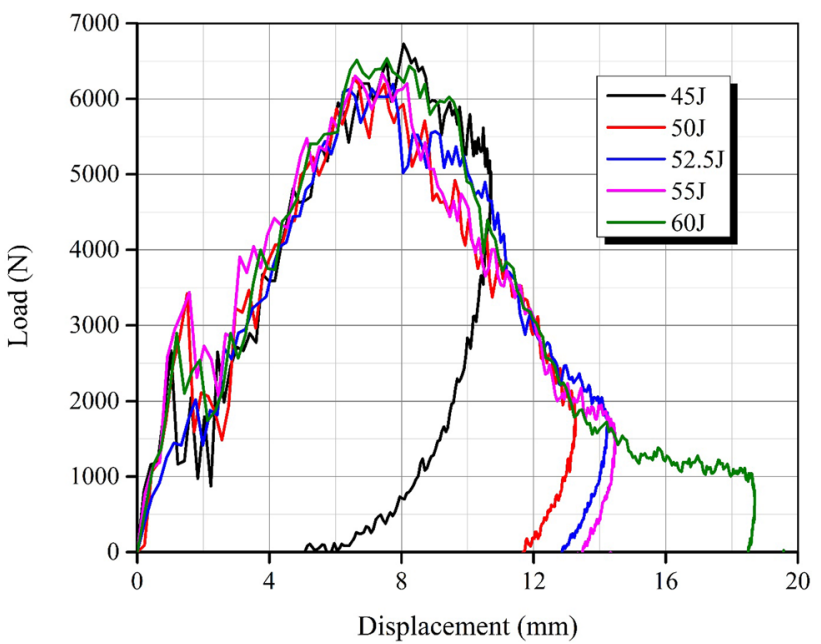

Fig. 3 Load $(\mathrm{N})$ versus displacement $(\mathrm{mm})$ curves of multilayered laminate

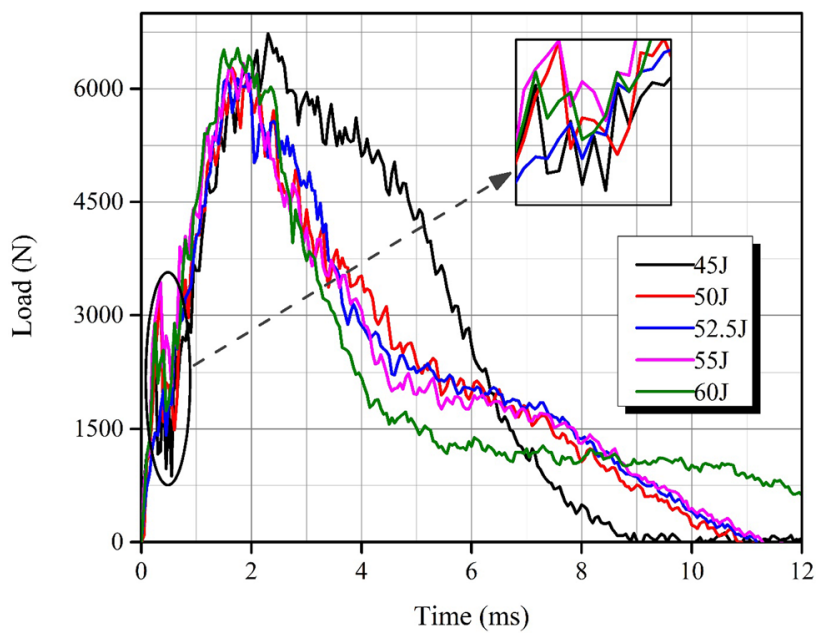

Fig. 4 Load (N) versus time (ms) graphs for multilayered laminate

noted and average of data set is used to plot the graphs as shown in Figs. 3, 4 and 5. The incipient energy is the potential energy stored in the impactor by virtue of its position, weight and energy available with spring-mass. 


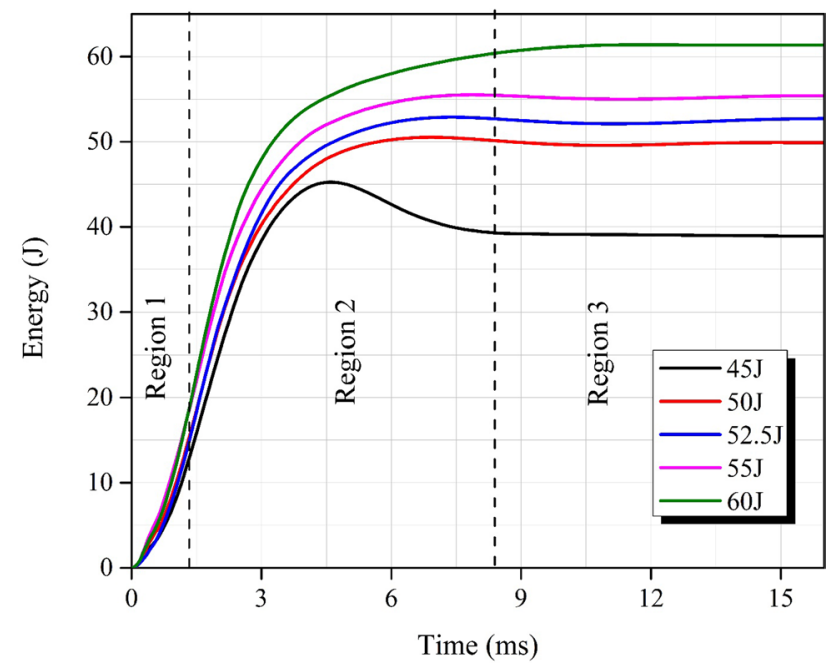

Fig. 5 Energy (J) versus time (ms) plots for multilayered laminate

\subsection{Load-energy-displacement-time plots}

Figure 3 presents load versus displacement graphs of laminates subjected to central transverse impact loads with a hemispherical steel tup. The increase in load is shown with the ascending portion followed by a descending portion. The tangent drawn for an imaginary straight line during ascending provides the stiffness of the laminate also known as transverse bending stiffness [18]. The maximum load recorded before the start of the descending portion is referred to as peak load. The closed type of curve represents the rebound phenomenon, the partially opened describes the penetration and open curve with its end portion parallel to transverse displacement defines the complete perforation of the composite [1]. It is clear that with the increase of impact energy the load-carrying capability gets decreasing, while the transverse displacement increases. The rebound phenomenon is shown by composite laminate for energy levels of $45 \mathrm{~J}$ and $50 \mathrm{~J}$ are witnessed with the close type of curves, whereas impact with $60 \mathrm{~J}$ resulted in complete perforation of the samples. In between partial perforation/penetration is noticed. The initial load drop also referred to as hertzian force which occurs due to matrix cracking, followed an inversely proportional trend with incipient energies as shown in Table 3. The immediate rise and drop of load in the graph stipulates delamination at interfaces of constituent layers. The laminate impacted at $45 \mathrm{~J}$ has shown maximum peak load. After peak load in all the energy levels, the displacement increased while the load getting decreased [36].

Figures 3, 4 and 5 presents the specific behaviour of hybrid composite laminate and in good agreement with the literature studies $[2,15,21]$. The graphical representation of load and energy values in respect to corresponding time, reveals the qualitative information of failure mechanism along with the transverse strength of the laminates [31]. In general, there is no delamination present in woven fabric reinforced composites [15], but due to the presence of thermoplastic sheet, the said delamination is noticed as shown in laminate impacted with $45 \mathrm{~J}$. The same is spotted in load versus time graph with sudden drop and rise peaks as shown in Fig. 4. The time taken to attain peak load is in decreasing trend with increasing incipient energy. The decrease in the stiffness of the hybrid laminate results in reduced time to reach peak load [37]. The load versus time graphs permit to note two load thresholds, namely hertzian load/first damage load and maximum/peak load.

The incipient energy versus time curves is shown in Fig. 5. The dynamic energy absorption process could be categories into three regions as separated by a dashed line in the graph. These regions are distinguished based on the type of damage appears during impact phenomenon. Indentation, dent formation, matrix cracking and delamination kind of failure modes fall into region 1 , whereas fibre fracture at in-plane and through-thickness direction, transverse displacement of a striker in penetrating the test sample is marked in region 2 with the rapid increase of curves. At last region 3 indicates the constant energy lines specifying the end of impact event [32]. The derived

Table 3 Direct impact parameters of multilayered laminate

\begin{tabular}{|c|c|c|c|c|c|c|c|}
\hline $\begin{array}{l}\text { Multilayered } \\
\text { laminate }\end{array}$ & Energy zone & $\begin{array}{l}\text { Impact } \\
\text { energy }(J)\end{array}$ & Peak load(N) & Hertzian load (N) & $\begin{array}{l}\text { Hertzian failure } \\
\text { energy }(J)\end{array}$ & $\begin{array}{l}\text { Peak displace- } \\
\text { ment (mm) }\end{array}$ & $\begin{array}{l}\text { Total dis- } \\
\text { placement } \\
(\mathrm{mm})\end{array}$ \\
\hline \multirow[t]{5}{*}{$\mathrm{G}_{8} \mathrm{PC}_{1} \mathrm{G}_{8}$} & Rebound & 45.0 & 6728.99 & 2668.39 & 1.30 & 8.06 & 5.89 \\
\hline & & 50.0 & 6164.38 & 3418.64 & 2.39 & 8.42 & 11.70 \\
\hline & Penetration & 52.5 & 6195.32 & 2018.70 & 1.96 & 7.74 & 12.84 \\
\hline & & 55.0 & 6334.54 & 3434.11 & 3.03 & 7.41 & 13.47 \\
\hline & Perforation & 60.0 & 6535.63 & 2892.69 & 1.56 & 7.55 & 18.48 \\
\hline \multirow[t]{2}{*}{ Average } & Present & & 6391.70 & 2886.50 & 2.04 & & \\
\hline & Evci and Gülgeç [1] & & 7868.70 & 1967.50 & 0.816 & & \\
\hline
\end{tabular}


energy parameters listed in Table 4 are determined using energy versus time curves.

\subsection{Damage evaluation}

Impact test parameters such as displacement, load and energy at considered incipient energies with respect to time are recorded from the data acquisition system and are listed in Table 3. Total transverse displacement of the impactor is increasing with increasing incipient energy while the peak displacement shows a gradual decline. The hertzian load, peak loads are closely concerned with material property. It is seen that, on comparison of the average values of hertzian load, peak loads and hertzian energy of hybrid multilayered composite laminate with the details provided by Evci and Gülgeç [1] there is an increase in hertzian load and corresponding energy along with a decrease in peak load. This result could be understood from the material properties of constituents. Due to week in-plane properties of polycarbonate, the peak load decreased. whilst due to its strong transverse properties and ductile nature the energy, applied load required for initial failure are increased.

The derived parameters in terms of various energies along with non-dimensional parameter i.e. ductility index are calculated and reported as shown in Table 4. Initiation energy $\left(E_{i}\right)$ is the amount of corresponding energy measured from the point of peak load. Elastic energy defines the rebound phenomenon. which is the amount of energy left to impactor to bounce back after striking. Elastic energy is expressed as the mathematical difference between max energy $\left(\mathrm{E}_{\max }\right)$ and the total energy available at the end of the impact event $\left(\mathrm{E}_{\text {total }}\right)$. From the tabulated values it is clear that, the amount of propagation energy and ductility index are directly proportional to the incipient energy. The different stages of damage progress along with impact energy can be witnessed from the amount of propagation energy. The initiation energy i.e. corresponding energy at peak load remains close to each other for tested impact energy levels. For rebound phenomenon, the elastic energy which is the energy given back to the impactor is more, unlike other energy zones.
The damage mechanism of laminate observed from rapid-I vision measuring system was demonstrated in Fig. 6 with different modes of failure. The energy applied by the striker over the surface of specimen will be absorbed in distinct modes, which consist of elastic deformation and irreversible damage such as matrix cracking, delamination, fibre fracture/splitting [33]. In addition to the said, the dent formation, shear plugging is noticed in current damage assessment which are commonly appear in monolithic ductile materials. Hence, it is presumed that by introducing thermoplastic sheet having high strain to failure appends the plastic deformation kind of failure to the catastrophically failed brittle glass fibre reinforced polymers as witnessed in the present investigation. For the same fiber volume ratio, the woven glass fiber reinforced polymer discussed in literature by Evci and Gülgeç [1] shown complete perforation of sample at $50 \mathrm{~J}$, whereas from the present investigation it is marked that, there is a substantial enhancement in the impact resistance in terms of damage area, growth and impact energy required to perforate the sample. The damage size is confined to the nose diameter of the impactor.

\section{Conclusions}

The important observations made from the present investigation on performance of multilayered hybrid laminate subjected to dynamic transverse impact are detailed as follows. The fabrication and testing of two component system made of thermoplastic and thermoset systems are done successfully. From the test results, it is witnessed that novel hybrid laminate could produced better results as compared with conventional hybrid composites and pure counterparts. The density of the hybrid laminate is reduced due to the incorporation of low-density polycarbonate about $19.17 \%$ as compared to pure glass fibre reinforced polymer. The impact energy required to perforate the laminate is about $60 \mathrm{~J}$ i.e. $16.66 \%$ of enhancement is noticed in energy required to perforate the hybrid laminate. The damaged area is particularly confined to the size of the impactor unlike the spread field observed for glass
Table 4 Impact characteristics of composite laminate

\begin{tabular}{llllll}
\hline $\begin{array}{l}\text { Initiation } \\
\text { energy }(J) \\
\left(E_{\mathrm{i}}\right)\end{array}$ & $\begin{array}{l}\text { Max. } \\
\text { energy }(J) \\
E_{\max }\end{array}$ & $\begin{array}{l}\text { Total energy at the } \\
\text { end of impact }(J) E_{\text {total }}\end{array}$ & $\begin{array}{l}\text { Elastic energy } \\
(J)\left(E_{\max }-E_{\text {total }}\right)\end{array}$ & $\begin{array}{l}\text { Propagation energy } \\
(J)\left(E p=E_{\text {total }}-E_{i}\right)\end{array}$ & $\begin{array}{l}\text { Ductility } \\
\text { index }\left(E_{p} /\right. \\
\left.E_{i}\right)\end{array}$ \\
\hline 29.73 & 45.24 & 39.17 & 6.06 & 9.44 & 0.31 \\
30.67 & 50.50 & 49.52 & 1.00 & 18.85 & 0.61 \\
28.58 & 52.87 & 52.09 & 0.78 & 23.51 & 0.82 \\
29.18 & 55.49 & 54.98 & 0.51 & 25.8 & 0.88 \\
28.56 & 61.37 & 61.33 & 0.04 & 32.77 & 1.14 \\
\hline
\end{tabular}




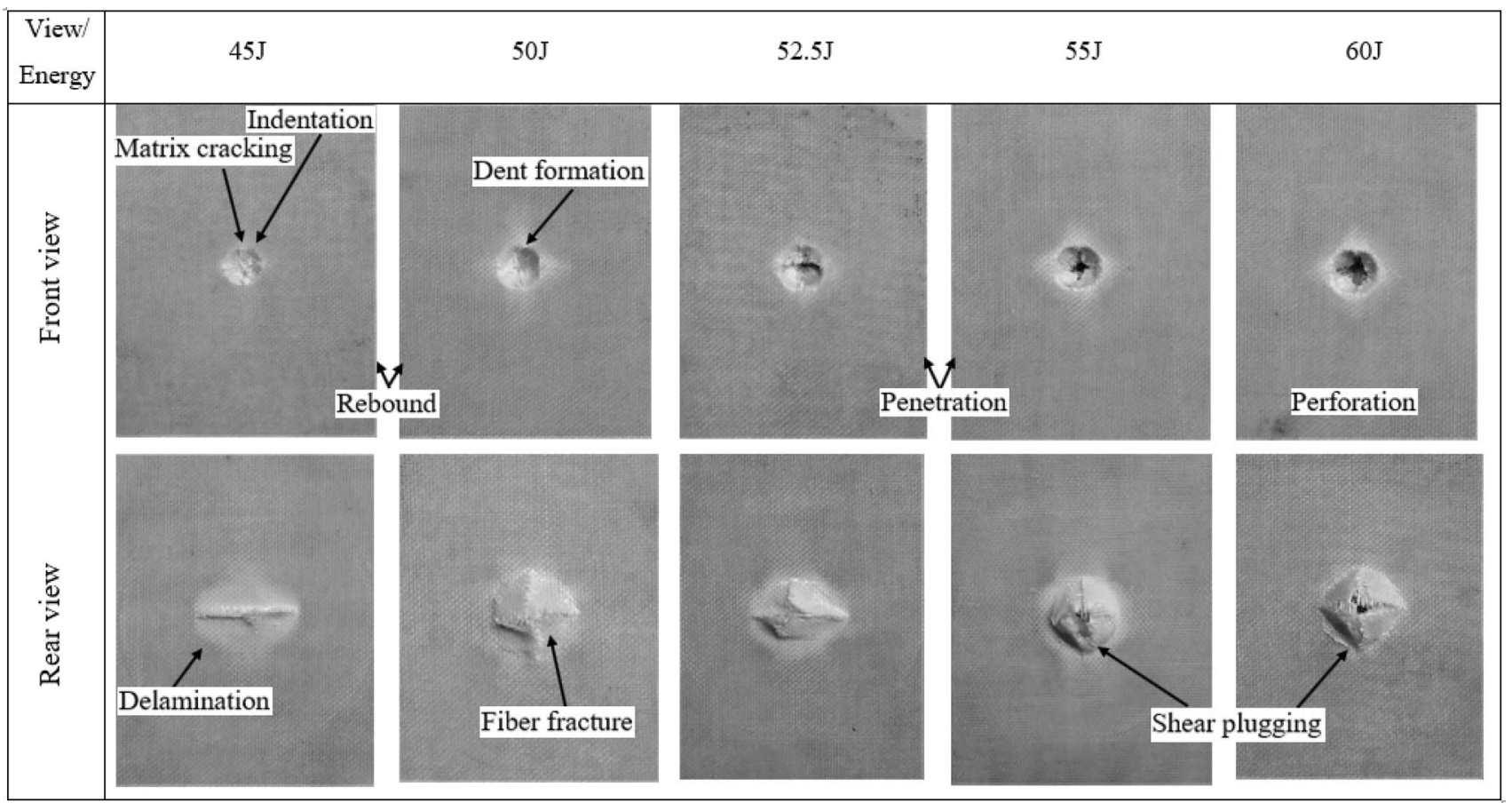

Fig. 6 Front and rear views of test specimens impacted at different energies

composite. The glass fibres are brittle and stiffer hence, glass fibre reinforced composite is having higher bending stiffness as compared to glass/polycarbonate, but due to better stain to failure property of polycarbonate improved the overall toughness of hybrid laminate. Further, the impact resistance offered by the laminate is improved via, the addition of plastic deformation to brittle failure of glass composites. The proposed novel hybrid laminate could be one of the potential solutions where impact loading cause loss of strength and also, find its usage in mechanical structures, armor systems, aeronautical and automobile parts.

Funding This research did not receive any specific grant from funding agencies in the public, commercial, or not-for-profit sectors.

\section{Compliance with ethical standards}

Conflict of interest The authors declare that they have no conflict of interest to disclose.

\section{References}

1. Evci C, Gülgeç M (2014) Effective damage mechanisms and performance evaluation of ceramic composite armors subjected to impact loading. J Compos Mater 48:3215-3236
2. Evci C, Gülgeç M (2012) An experimental investigation on the impact response of composite materials. Int J Impact Eng 43:40-51

3. Kretsis G (1987) A review of the tensile, compressive, flexural and shear properties of hybrid fibre-reinforced plastics. Composites 18:13-23

4. Icten BM, Kıral BG, Deniz ME (2013) Impactor diameter effect on low velocity impact response of woven glass epoxy composite plates. Compos Part B Eng 50:325-332

5. Hosseinzadeh R, Shokrieh MM, Lessard L (2006) Damage behavior of fiber reinforced composite plates subjected to drop weight impacts. Compos Sci Technol 66:61-68

6. Muhi RJ, Najim F, de Moura MFSF (2009) The effect of hybridization on the GFRP behavior under high velocity impact. Compos Part B Eng 40:798-803

7. Caprino G, Lopresto V (2001) On the penetration energy for fibre-reinforced plastics under low-velocity impact conditions. Compos Sci Technol 61:65-73

8. Thanomsilp C, Hogg PJ (2003) Penetration impact resistance of hybrid composites based on commingled yarn fabrics. Compos Sci Technol 63:467-482

9. Krishna CS, Shaikh AA, Makwana A (2020) Evaluation of hybridization effect on static and dynamic properties of the thermoplastic-based hybrid composites-an experimental study. Int J Polym Anal Charact 25:34-50

10. Ruhala LA, Engel RS (2000) An investigation of the effects of fiber volume fraction on the impact properties of fiber reinforced composite laminated plates. J Reinf Plast Compos 19:449-464

11. Arikan V, Sayman O (2015) Comparative study on repeated impact response of E-glass fiber reinforced polypropylene \& epoxy matrix composites. Compos Part B Eng 83:1-6

12. Lee Y-S, Kang K-H, Park O (1997) Response of hybrid laminated composite plates under low-velocity impact. Comput Struct 65:965-974 
13. Park R, Jang J (2001) Impact behavior of aramid fiber/glass fiber hybrid composites: the effect of stacking sequence. Polym Compos 22:80-89

14. Park R, Jang J (2001) Impact behavior of aramid fiber/glass fiber hybrid composite: evaluation of four-layer hybrid composites. J Mater Sci 36:2359-2367

15. Hosur MV, Adbullah M, Jeelani S (2005) Studies on the lowvelocity impact response of woven hybrid composites. Compos Struct 67:253-262

16. Zulkafli N, Malingam SD, Fadzullah SHSM, Razali N (2020) Quasi and dynamic impact performance of hybrid cross-ply banana/ glass fibre reinforced polypropylene composites. Mater Res Express 6:125344

17. Baucom JN, Zikry MA (2005) Low-velocity impact damage progression in woven E-glass composite systems. Compos Part A Appl Sci 36:658-664

18. Içten BM, Karakuzu R (2008) Effects of weaving density and curing pressure on impact behavior of woven composite plates. J Reinf Plast Compos 27:1083-1092

19. Liu D (2004) Characterization of impact properties and damage process of glass/epoxy composite laminates. J Compos Mater 38:1425-1442

20. Salehi-Khojin A, Bashirzadeh R, Mahinfalah M, Nakhaei-Jazar R (2006) The role of temperature on impact properties of Kevlar/ fiberglass composite laminates. Compos Part B Eng 37:593-602

21. Atas C, Icten BM, Küçük M (2013) Thickness effect on repeated impact response of woven fabric composite plates. Compos Part B Eng 49:80-85

22. Datta S, Krishna AV, Rao RMVGK (2004) Low velocity impact damage tolerance studies on glass-epoxy laminates-effects of material, process and test parameters. J Reinf Plast Compos 23:327-345

23. Icten BM, Kıral BG (2012) Impactor shape effect on low velocity impact response of woven glass epoxy composites. Adv Compos Lett 21:096369351202100502

24. Gustin J, Joneson A, Mahinfalah M, Stone J (2005) Low velocity impact of combination Kevlar/carbon fiber sandwich composites. Compos Struct 69:396-406

25. Sevkat E, Liaw B, Delale F, Raju BB (2009) Drop-weight impact of plain-woven hybrid glass-graphite/toughened epoxy composites. Compos Part A Appl Sci 40:1090-1110

26. Sevkat E, Liaw B, Delale F, Raju BB (2010) Effect of repeated impacts on the response of plain-woven hybrid composites. Compos Part B Eng 41:403-413
27. Sevkat E, Liaw B, Delale F (2013) Drop-weight impact response of hybrid composites impacted by impactor of various geometries. Mater Des (1980-2015) 52:67-77

28. Malingam SD, Ng LF, Chan KH et al (2018) The static and dynamic mechanical properties of kenaf/glass fibre reinforced hybrid composites. Mater Res Express 5:095304

29. Subramaniam K, Malingam SD, Feng NL, Bapokutty O (2019) The effects of stacking configuration on the response of tensile and quasi-static penetration to woven kenaf/glass hybrid composite metal laminate. Polym Compos 40:568-577

30. Dhar Malingam S, Subramaniam K, Lin Feng N et al (2019) Mechanical properties of plain woven kenaf/glass fiber reinforced polypropylene hybrid composites. Mater Test 61:1095-1100

31. Kaya G (2018) Comparison of the impact damage resistance of non-hybrid and intra-ply hybrid carbon/E-glass/polypropylene non-crimp thermoplastic composites. J Reinf Plast Compos 0731684418805561

32. Ying S, Mengyun T, Zhijun R et al (2017) An experimental investigation on the low-velocity impact response of carbon-aramid/epoxy hybrid composite laminates. J Reinf Plast Compos 36:422-434

33. Isa MT, Ahmed AS, Aderemi BO et al (2014) Drop weight impact studies of woven fibers reinforced modified polyester composites. LEJPT 13:97-112

34. Chitturi SK, Shaikh AA, Makwana AH (2019) Static analysis of thermoset-thermoplastic-based hybrid composite. Int J Struct Integr 11:107-120

35. ASTM D (2005) 7136/D 7136M-07. Standard test method for measuring the damage resistance of a fiber-reinforced polymer matrix composite to a drop-weight impact event

36. Reis PNB, Ferreira JAM, Santos P et al (2012) Impact response of Kevlar composites with filled epoxy matrix. Compos Struct 94:3520-3528

37. Richardson MOW, Wisheart MJ (1996) Review of low-velocity impact properties of composite materials. Compos Part A Appl Sci 27:1123-1131

Publisher's Note Springer Nature remains neutral with regard to jurisdictional claims in published maps and institutional affiliations. 